\title{
HAVANA POR LENTES SUJAS
}

\author{
Havana vista pelas lentes de um narrador-autor-personagem: \\ da ingenuidade ao oportunismo repleto de preconceitos
}

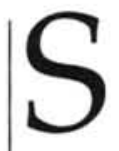

empre me impressionaram os escritores - em geral realistas - que preferiram, nas suas obras, narrativas ou dramáticas, fazer a denúncia de um mundo hostil, agressivo, degradado, sujo, e deter-se na pura e simples denúncia. Vêm-me à cabeça, como exemplos, o narrador João Antônio' e o dramaturgo Plínio $\operatorname{Marcos}^{2}$, ambos excelentes escritores, ambos paulistas, aliás. Plínio Marcos chegava mesmo a auto-denominar-se "repórter de um tempo mau", deixando claro que não oferecia soluções, mas mostrava os problemas. Isso decorria, talvez, da pressão das críticas que o perseguiam, numa época - a da ditadura militar - em que o escritor que não estivesse engajado na luta por uma nova socie- dade era considerado alienado, coisa que, evidentemente, nem João Antônio nem Plínio foram jamais. Plínio considerava que ao mostrar - e o teatro mostra mesmo - em suas peças o mundo da marginalidade, do crime, do vício, da miséria estava contribuindo de maneira significativa para indicar a necessidade da mudança. Com isso não concordava uma certa crítica que julgava ser seu teatro, embora de alta qualidade dramática, portador de uma certa confusão ideológica.

O caso de João Antônio é semelhante. O autor de Malagueta, Perus e Bacanaço ${ }^{3}$ sempre escolheu seus personagens entre aqueles que ele chamava os merdunchos: as prostitutas, os jogadores, os ladrões, malandros, proxenetas, vagabundos. En-

1. João Antônio (1937-1996), contista, autor, entre outros, de Malagueta, Perus e Bacanaço (1963), Ô copacabana (1968), Dedo-duro (1982), Malhação do Judas Carioca (1975). (N. Ed.)

2. Plínio Marcos (1933-1999), escritor e dramaturgo, autor, entre outros, de Barrela, Dois perdidos numa noite suja, Abajur lilás, Balada de um palhaço, Navalha na carne. Homens de papel. Quando as máquinas param. (N. Ed.)

3. João Antônio. Malagueta, Perus e Bacanaço. São Paulo: Ática, 1987. 
fim, a gente que fazia as delícias dos tiras, achacadores e corruptos. Sua vida, tanto quanto a vida de Plínio, foi um suceder-se de rupturas e de protestos; ambos sabiam beber e bebiam muito, forma, também, de escapar à angústia que a vida concreta provocava na sua sensibilidade, tão fina quanto parecia ser grosso o mundo que eles preferiam retratar.

Não indicavam caminho algum, real, concreto, para a saída dos seus personagens, tão confusamente, afinal, pareciam eles estar determinados por sua condição social. Mas, por outro lado, tampouco escreviam monitorados pela explícita angústia existencial de um Samuel Beckett, de um Franz Kafka (sem que se queira comparar qualitativamente os quatro escritores). Nunca disseram que o mundo era assim e que assim devia continuar. Não tinham a, pelo menos aparente, conformidade dos angustiados metafísicos.

Foram ambos, de certa maneira, jornalistas, tanto quanto ficcionistas: o repórter se insinuava sempre nas palavras de João Antônio, afinal o que tinha, de fato, familiaridade com a profissão; mas era o outro que se denominava, como vimos, "repórter".

Nenhum dos dois, por outro lado, colocou-se explicitamente como personagem de suas histórias. É claro que o narrador-autor sempre pode estar, e de fato está presente em seus personagens. Mas o pudor de ficcionista o impede de identificar-se com o personagem, de dar seu nome ao personagem.

Com toda a certeza, esse caráter autobiográfico, esse viés confessional, está presente em muitos outros escritores: penso de início em Hemingway, também ele jornalista, e em Henry Miller.

Miller com muito mais propriedade; dele diz, mesmo, Otto Maria Carpeaux, na sua magnífica História da literatura ocidental: "O sexualismo desenfreado e a permanente miséria material são os únicos temas dos seus livros escritos com franqueza quase pornográfica (...). Mas também com cansativa monotonia, pois constituem uma volumosa autobiografia do autor que, com ingenuidade colossal, se coloca no centro do mundo, sem demonstrar seu direito para tanto" 4 .

\section{ATO PROMÍSCUO}

E, com esta citação, chega a hora de falarmos, afinal, no tema deste artigo, que o título, aliás, introduz e provoca.

Referimo-nos, de fato, ao escritor cubano Pedro Juan Gutierrez e a seu ... romance? autobiografia? Ao volume, enfim, que, editado pela Companhia das Letras, e traduzido por José Rubens Siqueira, chamou-se Trilogia suja de Havana.

Aqui se verifica, de início, que o autor, explicitamente, segue a trilha aberta por Henry Miller: muito sexo, muita miséria e, principalmente, o colocar-se no centro das ações descritas, portador daquilo que Carpeaux chamou "ingenuidade colossal" mas que, nos dias que correm, e com menos ingenuidade, poderse-ia chamar oportunismo.

Dada a enorme sucessão de cenas de sexo descritas - e sem que isso implique nenhum moralismo, que de fato não existe $-o$ autor-narrador-personagem faz de si mesmo um esplêndido atleta sexual,

4. CARPEAUX, Otto Maria. História da literatura ocidental. Rio de Janeiro: O Cruzeiro, 1959. 
cujas façanhas, naturalmente, a ninguém é dado comprovar, já que, a essa altura, acabam por ser confundidas com a ficção.

Ao passo que Henry Miller

considera o ato sexual alguma coisa de solene, algo que merece atenção e certa sacralidade, o escritor cubano se empenha em vulgarizar a (sua?) vida sexual.

Visto que em praticamente todos os capítulos de sua Trilogia (e ela tem perto de sessenta capítulos) pelo menos uma cena de sexo, e às vezes várias, são enfocadas, o que temos é uma sucessão de variantes sexuais, todas elas ubicadas em ambientes de miséria, sujidade, promiscuidade, depressão, doença, e, na maior parte das vezes, de uma bebedeira pobre, de rum sempre barato e de má qualidade.

Será que estamos desejando que o autor se especialize na literatura rosa? Queremos que escreva poemas românticos? Nem pensar. No entanto, seja na sua miserável cobertura voltada para o mar, cheia de ratos, baratas e outros animais variados, decadente e derruída, vizinha de uma privada coletiva que cheira a merda - merda, aliás, é uma das palavras-chave do romance - seja no Malecón havanero, calçadão que acompanha a borda do mar em Havana, o encontro é quase sempre com uma negra que cheira mal, é gorda, grita em demasia e tem preferência explícita por variações humilhantes do ato propriamente dito.

A par de uma representação da vida e do ambiente da cidade de Havana marcada pela imundície, pela carência e pontilhada de mendigos, prostitutas, ladrões e obsessivos sexuais, o escritor demonstra sua preferência pelo enfoque a uma parcela da sociedade absolutamente desamparada isso num país onde o amparo à sociedade, com prejuízo, às vezes, da liberdade individual, tem sido levado tão a sério que, com ele, se procura justificar as restrições de outros gêneros que motivam as críticas ao regime. Seus personagens não conseguem trabalhar, ou se o fazem, é em subocupações que não bastam sequer para a sobrevivência; morrem, literalmente, de fome, quando se sabe que a cada cidadão cubano é garantido pelo Estado pelo menos o mínimo. Não obstante, a esses mesmos personagens famintos e moribundos, sempre sobram forças para tomar rum, fumar (com que dinheiro?) e praticar o sexo (com que energia?) .

A julgar por sua experiência, se colocássemos lado a lado todos os personagens praticantes de felatio, cunnilinguus, homossexualismo, sexo grupal, voyeurismo, masturbação e prostituição pura e simples, de noite, sentados nos muros do Malecón, não poderíamos ver o mar, tal o número de personagens desse tipo que o autor pinça para enfeitar as páginas de seu romance. Teríamos, dessa forma, uma longa sucessão de miseráveis que contradiz, de fato, a realidade, colhida por inúmeros outros testemunhos.

Não se trata de dizer que a Havana dos anos noventa - época do romance - era fácil e tranqüila, muito pelo contrário. Estávamos nos anos do chamado período especial, e os cubanos em geral sofreram muitas privações por esse tempo. Mas, ao passo que o problema da moradia era candente, com edifícios arruinados, casas trans- 
formadas em cortiços e apartamentos superlotados, a sociedade se empenhava em conseguir trabalho para todos, não o tipo de trabalho ideal que cada um sonhava, mas aquele que era possível a fim de prover, ao menos, o acesso ao mínimo - aliás garantido pobremente pela chamada libreta, a cesta básica mensal dos cubanos.

Ao apresentar seus personagens como uma sucessão de vagabundos o autor violenta a realidade, em benefício da ficção - a qual, no entanto, apresenta como uma fotografia da sua realidade.

Outro ponto delicado da obra de Pedro Juan Gutierrez está na forma como o autor descreve a mulher em seu romance; personagem constante, uma vez que, como foi dito, o sexo forma o grosso da história (com perdão do trocadilho), a mulher aparece repetidamente como prostituta, biscateira, ou como eventual companheira de prazer, e nunca mais do que isso. É natural que um autor escolha a forma como contará sua história e a forma como apresentará seus personagens, mas, aqui, voltamos ao ponto inicial: dado que ele escolhe a autobiografia, ficamos necessariamente presos à noção de realismo fotográfico. É a história verídica de Pedro Juan, que aqui se conta?

\section{SERVO DO PRECONCEITO}

Mais um motivo de surpresa emerge desse romance: são os explícitos preconceitos do autor. Alguns exemplos (esco- lhidos dentre os que podem ser citados):

"Os negros muito negros sempre têm esse cheiro acre demais".

"As mulheres - e as negras, mais ainda - não gostam de deixar nada para depois".

"Algumas (mulheres) já haviam conseguido botar um médico na armadilha. Em sua armadilha vaginal, quero dizer".

"É preciso ter cuidado com essas negras. Sempre agressivas. “

"Aqui só vivem negros, velhas desastrosas..."

"Mulheres com caráter viram um manjar de coco jorrando calda quando um homem as domina bem".

"Ao seu lado um negro, orangotango enorme, que a abraçava..."

É de se notar que todos os exemplos acima apontados referem-se a falas do narrador, e nunca de outros personagens.

Em suma, apesar de nunca conseguir justificar aquilo que Otto Maria Carpeaux chamou "ingenuidade", ou seja, a colocação de seu próprio personagem como centro do universo, o autor conseguiu, sem dúvida, chamar a atenção para a sua obra. Trata-se de um narrador hábil, que se apropriou do estilo Henry Miller e resolveu sobreviver inventando uma mescla de fatos verídicos, experiências pessoais, histórias do folclore urbano havanero - algumas já excessivamente conhecidas - e uma grande dose de imaginação sexy. Alcançou, com isso, despertar a curiosidade de um certo público da Europa, sempre pronto a consumir qualquer coisa que fale, de modo picante e provocador, da vida cubana. O turismo sexual está aí, que não 
nos deixa mentir. E o caminho para o sucesso na América estava aberto. Note-se que o autor é cubano, vive em Havana, onde não foram publicados esses textos, e sobrevive pagando, com dólares, a comida cubana que a sociedade de trabalhadores produz.

Não quero dizer que um escritor não seja também um trabalhador. A quem o diria! Mas causa espécie esse escritor que produz para exportação, dá de Cuba e de sua gente um retrato deformado, coloca-se a si mesmo como uma espécie de Casanova tropical, aquilo que os próprios cubanos cha- mam de un castigador e depois escolhe continuar vivendo naquele ambiente que, de forma tão deprimente, desdenhou.

Volto a ler Plínio Marcos e João Antônio; curioso como amavam os seus personagens, como lhes davam dignidade. Hay que endurecerse, pero sin perder la ternura jamás. Havia uma dor honesta no dramaturgo como no romancista, mágoa verdadeira de quem comparte e sofre junto. Este PJGutierrez de agora abranda-se, falsifica e volta ao local do crime quando lhe interessa.
Resumo: A autora trata da obra Trilogia suja de Havana, de Pedro Juan Gutierrez, editada recentemente no Brasil pela Companhia das Letras. Destaca como o autor retrata a cidade de Havana, sua gente, seus conterrâneos em passagens com grosseiros preconceitos contra a mulher e o negro. Como peça composta por uma estratégia que se afirma, ao mesmo tempo, autobiográfica e ficcional, insere o leitor numa Havana promiscua, fétida e decadente. $\mathrm{O}$ artigo discute ainda como Pedro Juan Gutierrez subtrai a realidade de seu livro e faz dele literatura de exportação, comercialmente conveniente inclusive para esquentar a imaginação dos que praticam o turismo sexual.

Palavras-chave: Trilogia suja de Havana, mulher, negro, sexo, preconceito, Havana
(Havana, through dirty lenses)

Abstract: The author discusses Pedro Juan Gutierrez's book Trilogia suja de Havana (Dirty trilogy of Havana), launched recently in Brazil by publisher Companhia das Letras. He talks about how the author pictures the city of Havana, its people, and his compatriots in passages where there is gross bias against women and black people. Composed by a strategy that claims to be, at the same time, autobiographical and fictional, it places the reader in a promiscuous, fetid and decadent Havana. The author also discusses how Pedro Juan Gutierrez subtracts reality from his book and turns it into literature for export, commercially convenient even to heat up the imagination of those who practice sexual tourism.

Key words: Dirty trilogy of Havana, woman, black people, sex, bias, Havana 